Article

\title{
Establishment and Application of the Spatial Decomposition Method (SDM) for Tunnels Passing Through Large Karst Caves
}

\author{
Zhenyue Shi ${ }^{1} \oplus$, Qingbiao Wang ${ }^{1,2,3,4, *}$, Chuming Pang ${ }^{5, *}$, Yueming Yuan ${ }^{6}$, Fuqiang Wang ${ }^{6}$, \\ Hongxu Song ${ }^{5}$, Jichang Liu ${ }^{7}$, Zijie Zhang ${ }^{7}$, Rongbo Sun ${ }^{8}$ and Yan Liu ${ }^{9}$ \\ 1 College of Safety and Environmental Engineering (College of Safety and Emergency Management), \\ Shandong University of Science and Technology, Qingdao 266590, China; 201881010015@sdust.edu.cn \\ 2 State Key Laboratory of Mining Disaster Prevention and Control Co-Founded by Shandong Province and the \\ Ministry of Science and Technology, Shandong University of Science and Technology, Qingdao 266590, China \\ 3 National Engineering Laboratory for Coalmine Backfilling Mining, \\ Shandong University of Science and Technology, Tai'an 271019, China \\ 4 College of Resources, Shandong University of Science and Technology, Tai'an 271019, China \\ 5 College of Energy and Mining Engineering, Shandong University of Science and \\ Technology, Qingdao 266590, China; 201983010016@sdust.edu.cn \\ 6 College of Civil Engineering and Architecture, Shandong University of Science and Technology, \\ Qingdao 266590, China; 201883040083@sdust.edu.cn (Y.Y.); 201983040061@sdust.edu.cn (F.W.) \\ 7 No.1 Engineering Development CO., Ltd. of China Railway 14th Bureau Group., Rizhao 276826, China; \\ liujichang1586@163.com (J.L.); zhangzijie123@163.com (Z.Z.) \\ 8 Jinan Rail Transit Group CO., Ltd., Jinan 250101, China; srb-01@163.com \\ 9 Shandong Zhengyuan Construction Engineering Co., Ltd., Jinan 250101, China; lyan-310@163.com \\ * Correspondence: skd990748@sdust.edu.cn (Q.W.); 201981010010@sdust.edu.cn (C.P.)
}

Received: 19 July 2020; Accepted: 13 October 2020; Published: 15 October 2020

\begin{abstract}
Karst tunnels commonly pass through large karst caves during their construction and operation. Although treatment technologies are relatively mature, a systematic treatment method to guide the selection of treatment technologies is lacking. To solve this problem, a spatial decomposition method (SDM) of large karst caves is proposed that is based on analyzing the spatial relationship between tunnels and karst caves and summarizing the relevant treatment techniques. In this method, the space between the tunnel and the cavern is divided into eight parts using a space dividing line (SDL), which makes the spatial position relationship between the tunnel and cavern more intuitive. A geometric model of the SDM is established, and the numerical values of each geometric parameter are determined by field surveys and drawings. Constructing a three-dimensional spatial diagram by applying relevant parameters to the geometric model provides a reference for selecting a treatment technology. The SDM of the arch top, arch bottom, and two wings matching the treatment technology is proposed. Seven principles of technical selection-namely, safety, convenience, scientificity, sustainability, economy, feasibility, and openness-are mentioned in order to overcome the difficulty of technology selection due to such factors as technological diversity, materials, equipment, and environment. Finally, the SDM is used to solve the problem of the Shangyuan tunnel passing through a large karst cave. The implementation of the SDM in tunnel construction would represent a significant breakthrough and has important engineering value in solving the problem of tunnel passes through large karst caves.
\end{abstract}

Keywords: spatial decomposition method; spatial decomposition line; huge karst cave; geometric model; treatment technology 


\section{Introduction}

Karst is widely distributed around the world, and it causes great inconvenience to the achievement of engineering construction projects. Regions in the southwest of China, such as Yunnan and Guizhou, as well as other regions of China, are typified by steep hills and plenty of Karst terrain [1-4]. With the continuous improvement of China's "western development" strategy, the prevalence of karst tunnel construction is increasing rapidly, and various technical problems of karst tunnels are constantly appearing [5,6]. Passing through a large karst cave can be considered as one of the main difficulties in tunnel construction that will impose higher theoretical and technological requirements on karst cave treatment. The study aims to identify and analyze a powerful new method for the implementation of karst tunnels.

In this regard, there are many relevant studies and engineering applications carried out by scholars that deal with large karst caves revealed during tunnel construction, the main aspects of which are exemplified as follows: Li et al. [7] treated a karst cave in a tunnel floor using the beam and plate method, and also used backfilling to treat the revealed karst cave. Cui et al. [8] introduced the requirements of karst tunnel treatment, grouting materials, construction procedures, and effect detection. Shi et al. [9] and Wang et al. [10] studied the application of alkali-resistant fiberglass grouting material in karst cave treatment. Fan et al. [11] found that the methods of pile foundation treatment at the bottom of the tunnel, strengthening the surrounding rock of the tunnel by full-section grouting, and supporting the top of the karst tunnel with an anchor net and shotcrete are effective. Chen et al. [12] focused on the Naqiu tunnel hall karst cave project, and used the pile-bearing platform-retaining wall method to control the karst cave. Garasic et al. [13] designed a $58 \mathrm{~m}$ bridge through a large karst cave. Yang et al. [14] proposed a new controlled grouting method and grouting material for the pre-reinforcement of the underwater karst area of a shield tunnel. Li et al. [15] showed that the treatment technology of an ultralarge karst cave in the Yawan tunnel, which is treated at the bottom of the tunnel by a continuous composite beam bridge, and the wall of the karst cave is treated by the combined support of an anchor net and spray. Zhang et al. [16] reported the treatment of large karst caves encountered during the construction of the Limushan tunnel by backfilling. Yuan et al. [17] treated a large karst cave in the Shangjiawan tunnel with plugging and crossing methods. Tan [18] analyzed the advantages and disadvantages of longitudinal retaining walls, pile foundation-bearing platforms, and backfilling in tunneling through large karst caves from the perspectives of cost, safety, convenience, and time limitations. He [19] used a roundabout method to turn a revealed large cave into a side hidden cave. Tian [20] and Wang [21] analyzed the safety problems of limestone during mining.

Based on the results of the above scholars, in view of the treatment technology of large karst caves revealed by tunnels, researchers have combined the practical projects and summarized the rich experience in treatment technology. In general, various technologies can be adopted to treat large karst caves. However, these existing technologies are lacking in commonality because they are based on specific engineering characteristics. There is a lack of a systematic method to guide the selection of one or more treatment technologies. To guarantee that the tunnels through large karst caves can achieve the purposes of convenience, high efficiency, safety, and systematicity, it is necessary to construct a complete set of technologies in order to achieve the comprehensive treatment of tunnels through large karst caves.

To overcome the abovementioned challenges, this paper describes a guiding method for tunnels through large karst caves and a complete set of technical measures. In order to achieve this goal, the following steps will be taken: (1) propose a spatial decomposition method (SDM); (2) establish a geometric model of SDM; (3) determine the numerical value of each parameter of the geometric model through field survey (surveying, drilling, mapping); (4) analyze the complete set of treatment technologies; (5) combined with the practical engineering of karst cave in the Shangyuan tunnel, SDM and its treatment technology are applied systematically. The research design of this paper is illustrated in Figure 1. 


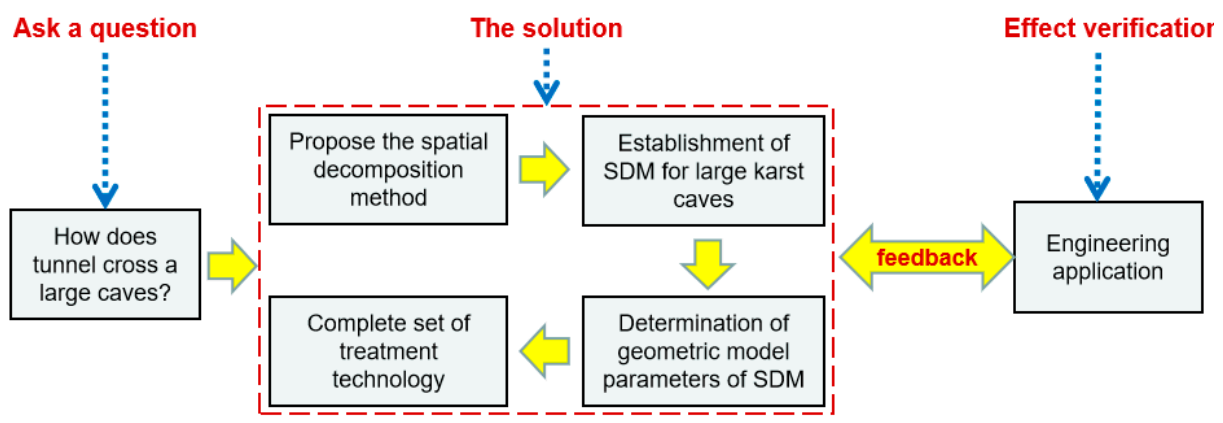

Figure 1. Research design.

\section{Establishment of SDM for Large Karst Caves}

\subsection{General Situation}

When large karst caves are found in tunnel construction, the spatial location relationship between the tunnels and karst caves should be determined, and then a specific construction scheme must be formulated. The spatial relationship cannot provide detailed evidence of the preparation of construction technology, because we also need to satisfy certain necessary conditions such as karst cave filling, water content, and surrounding rock stability. Then, the SDM is proposed by taking into account the treatment process and technology of the bottom, top, and two sides of the cavern through the tunnel. The SDM divides the cave space into different spatial parts when a tunnel passes through a large karst cave, which provides technical solutions for subsequent cavern management.

\subsection{Establishment of SDM}

Owing to the diversity and complexity of cave development, the edges of caves are irregular. We assume an irregular karst cave as shown in Figure 2, and take as the analysis object one of the typical sections, labeled typical section I, as shown in Figure 3.

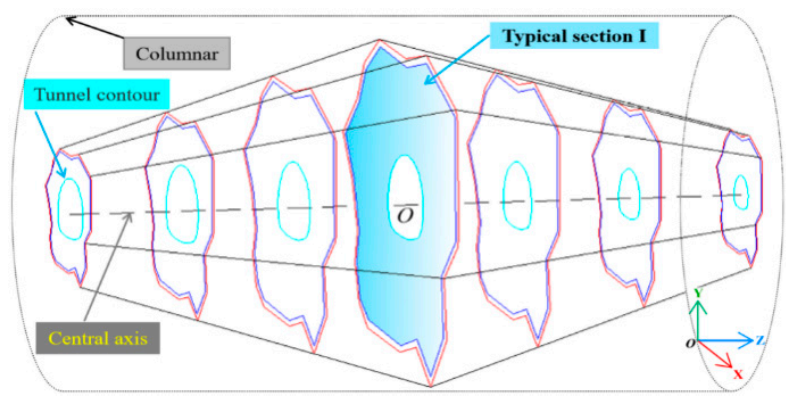

Figure 2. Schematic diagram of the spatial relationship between the karst cave and tunnel.

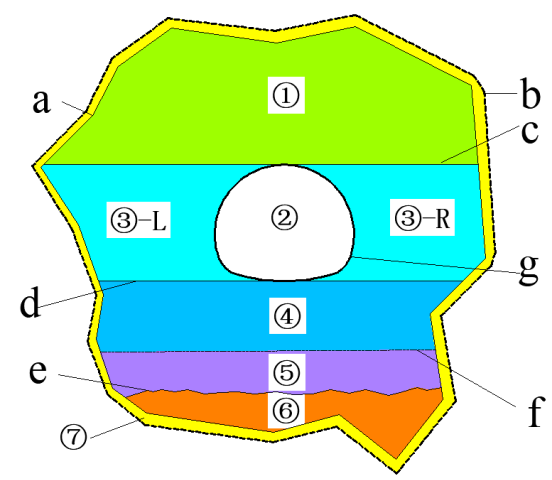

Figure 3. Schematic diagram of the SDM (spatial decomposition method). 
According to Figures 2 and 3, the surrounding wall of the karst cave space is the cave outline. In fact, it is a three-dimensional (3D) closed surface of the cave contour. Here, typical section I (Figure 2) is selected, such that the cave contour line is a closed curve, as shown in the middle line in Figure 3. Owing to the erosion of the surrounding rocks in the process of karst development, a certain thickness of an unstable structure layer could be formed in the surrounding rock of the karst cave. The tunnel outline (line g) is the shape of the outermost protective layer in the design. At the top of the tunnel profile, we draw an artificial tangent called the tunnel top line (line c), while at the bottom of the tunnel contour we draw a tangent called the tunnel bottom line (line $\mathrm{d}$ ). There is typically a certain thickness of fillings in karst caves, which may be gravel, clay, sand, etc., and the treatment of fillings is also an important part of karst treatment; therefore, the filling line (line e) should be drawn. Water is the most common filling material in karst and has a significant impact on tunnel construction, which is represented by the water level (line $\mathrm{f}$ ). Lines a-g are collectively referred to as spatial decomposition lines (SDLs). SDLs are continuous surfaces rather than closed curves or line segments. For example, the water level (line f) represents the water surface in the project.

Using SDLs, the cave space can be divided into eight space parts: the upper space of the cave (1)), the tunnel cavity space (2)), the karst cave space on the two wings of the tunnel (3)), the arch bottom cave space (4), the water space (5), the filling space (6), and the unstable surrounding rock space (7)). The karst cave space on the two wings of the tunnel can be divided into the left and right space parts, respectively, (3)-L and (3)-R. The specific space numbers are shown in Figure 3 (1)-(7).

\subsection{Geometric Model of SDM}

To facilitate the application of SDM, the geometric model of SDM should be established. Because the section of the tunnel and the karst cave along the direction of tunnel excavation are in a closed ring, a cylindrical coordinate system is chosen for the mathematical model, as shown in Figures 2 and 4 . The central axis of the tunnel is taken as the $Z$-axis, and the intersection of the tunnel entrance and the karst cave is set as the origin $Z=0$. Additionally, a cartesian coordinate system is set up. The reason for setting up two coordinate systems is that lines $a, b$, and $g$ in Figure 3 are circular closed curves, which are more conveniently represented in a cylindrical coordinate system, whereas lines $\mathrm{c}$ and $\mathrm{d}$ and other straight lines are more conveniently represented in a cartesian coordinate system. The two established coordinate systems are shown in Figure 5.

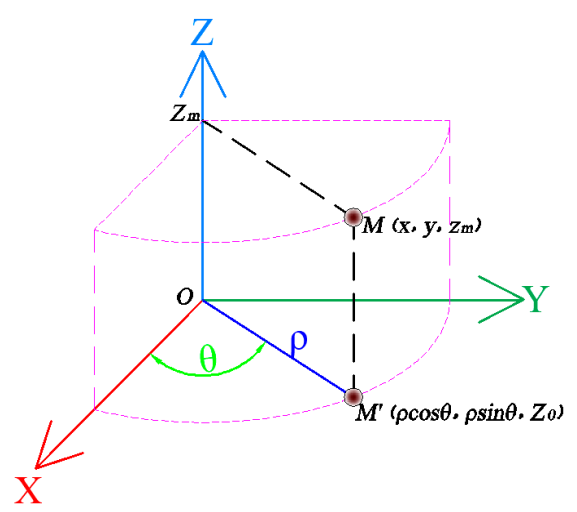

Figure 4. Schematic diagram of the cylindrical coordinate system. 


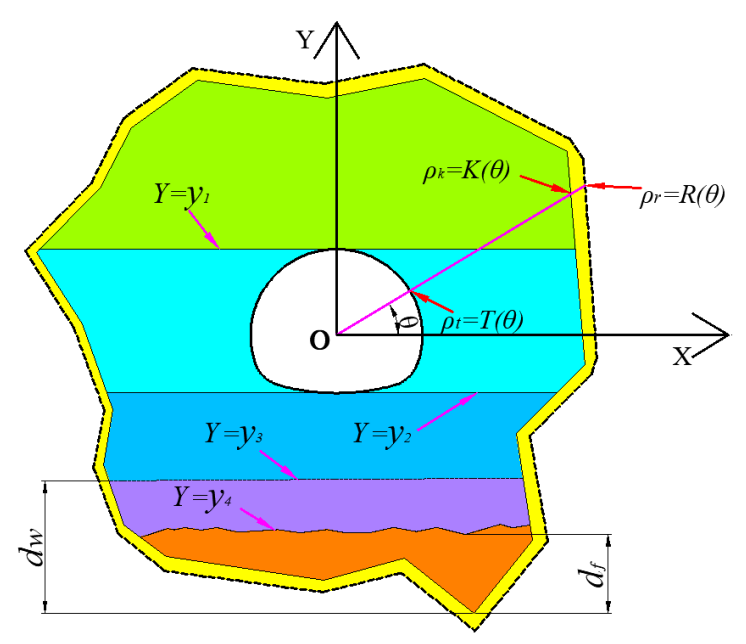

Figure 5. Mathematical model of the SDM.

Let $M=\left(x, y, z_{m}\right)$ be any point in the surrounding rock of the karst cave, and convert it into a cylindrical coordinate system, which can be expressed as follows [22]:

$$
\left\{\begin{array}{c}
x=\rho \cos \theta \\
y=\rho \sin \theta \\
z=z_{m}
\end{array}\right.
$$

where the geometric meaning of $\rho$ is polar diameter, which is the length of $\mathrm{OM}^{\prime}$, but, in practice, the cave is not a regular cylinder, such that the value of $\rho$ changes. The geometric meaning of $\theta$ is the polar angle, which is the angle between $\mathrm{OM}^{\prime}$ and the positive $X$-axis. The geometric meaning of $Z$ is the plane parallel to plane XOY.

The SDL (line a-g) in Figure 3 is converted into a polar coordinate system, as shown in Figure 5. The following formulae are obtained:

$$
\begin{aligned}
& \rho_{k}=K(\theta), \\
& \rho_{r}=R(\theta), \\
& \rho_{t}=T(\theta) .
\end{aligned}
$$

$\rho_{k}$ is the geometric expression of the cave contour (line a), $\rho_{r}$ is the geometric expression of the surrounding rock stability edge line (line b), $\rho_{t}$ is the geometric expression of the tunnel contour line (line g), and $\theta$ is the angle between the counterclockwise direction of the polar coordinate axis $\rho$ and the $X$-axis.

According to the cartesian coordinate system:

$$
\begin{aligned}
& Y=y_{1}, \\
& Y=y_{2}, \\
& Y=y_{3}, \\
& Y=y_{4},
\end{aligned}
$$

where $y_{1}$ is the geometric expression of the tunnel top line (line c), $y_{2}$ is the geometric expression of tunnel bottom line (line $d$ ), $y_{3}$ is the geometric expression of the water level line (line $\mathrm{f}$ ), and $y_{4}$ is the geometric expression of the filling line (line e). 


\section{Determination of the Geometric Model Parameters of SDM}

After the geometric model of SDM is established, many parameters are involved in the model, such as the cave contour $\left(\rho_{k}\right)$, the surrounding rock stability edge line $\left(\rho_{r}\right)$, the tunnel contour line $\left(\rho_{t}\right)$, and the tunnel top line $\left(y_{1}\right)$. These parameters can be obtained by field investigations and measurements, and then input to the geometric model to draw a 3D spatial diagram of the karst cave and tunnel. The figure can also describe the comprehensive development of the surrounding rock crushing, water-bearing, and filling space of the tunnel, thereby providing a spatial reference for the selection of subsequent treatment methods.

(1) Determination of the tunnel central axis, contour line, tunnel top, and bottom line.

The tunnel central axis is the reference line of the geometric model for the SDM. The central axis and the outline of the tunnel can be determined by the method of backward intersection. Starting from the tunnel entrance, measured sections are acquired at intervals of $D_{1}$, as shown in Figure 6, with $Z_{1}-Z_{i}$, where $D_{1} \leq 5 \mathrm{~m}$ and the total of the cave is not less than five measured sections. The tunnel top line (line $\mathrm{c}$ ) and the tunnel bottom line (line $\mathrm{d}$ ) were determined by the engineering survey method. Finally, each line (line c) could be connected to the top surface and each line (line d) to the bottom surface.

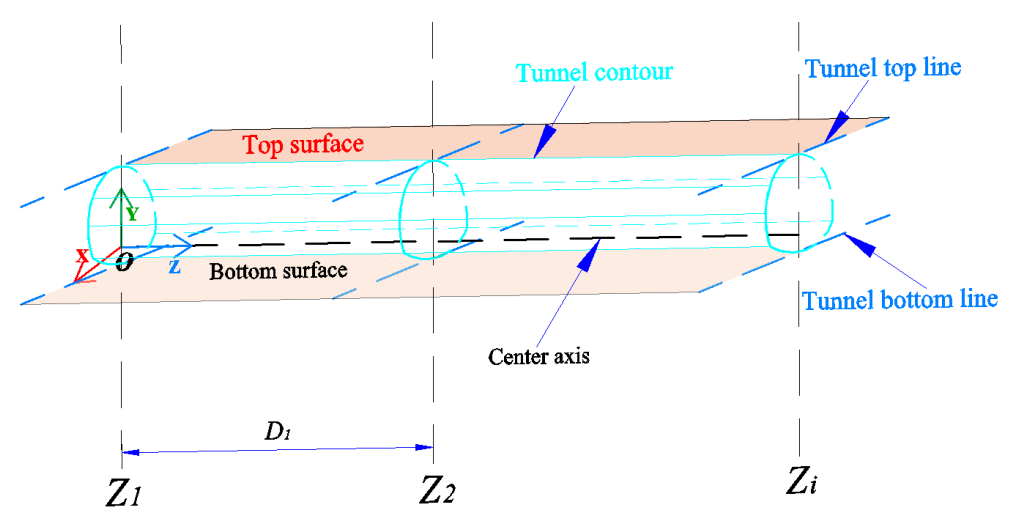

Figure 6. Location measurement of each line of the tunnel body.

(2) Determination of the cave contour line (line a).

A cavity formed in a rock mass is also called a cave. There are many ways to measure the space of the cave development, such as 3D laser scanning technology [23-26] and laser ranging. In this project, an angle-laser rangefinder was used which can display both the angle and distance. As shown in Figure 7, when laser ranging is performed on each monitoring point of section $Z_{i}$, the laser ranging equipment cannot be conveniently installed at the corresponding $\mathrm{O}$ point of the central axis of the tunnel, and thus a tripod is used to set the laser equipment at the bottom of the cave, directly below point $\mathrm{O}$. By adjusting the laser measuring angle, the circular distance measuring point density can be adjusted, and the value of the angle can be adjusted based on the size of the cave to ensure that each section has at least 12 points.

Finally, the measurement points of the $Z_{1}-Z_{i}$ section are plotted in a cylindrical coordinate system, and the points of the same section are joined to form rings. The measurement points $(i-1)-(i-n)$ of section $Z_{i}$ are shown in Figure 7 . The measurement points of different sections are connected by linear segments, as shown in Figure 7 . The measurement points (1-2)-(i-2), where " $i$ " is the section number, form the 3D structure of the karst cave.

When laser ranging is carried out in section $Z_{i}$, the parameters $\theta$ and $\rho_{k}$ of the geometric model cannot be directly measured unless a geometric calculation is employed. Therefore, the geometric relationship is established, as shown in Figure 8. Laser ranging equipment can read the distance $\left(d_{2}\right)$ between the laser (point $E$ ) and the proposed measurement point (point $M$ ) directly. The measurement angle can be read $(\alpha) . d_{3}$ is the height of the laser equipment tripod, which can be directly measured in the field. 


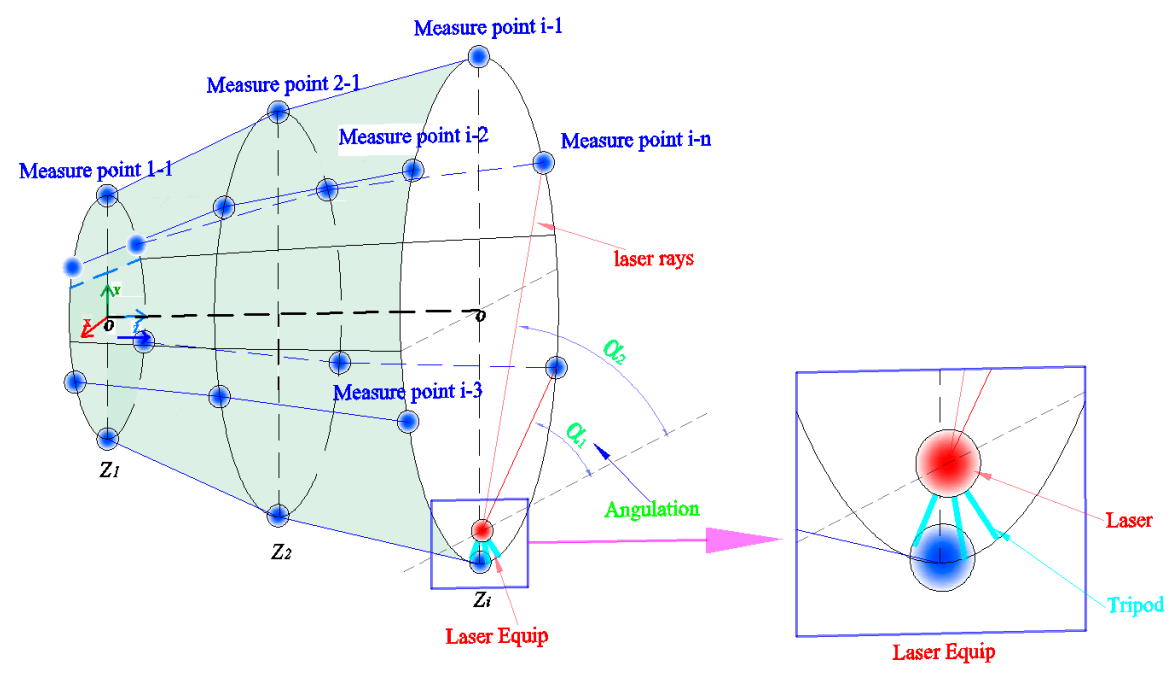

Figure 7. Schematic diagram depicting the method for determining the cave contour.

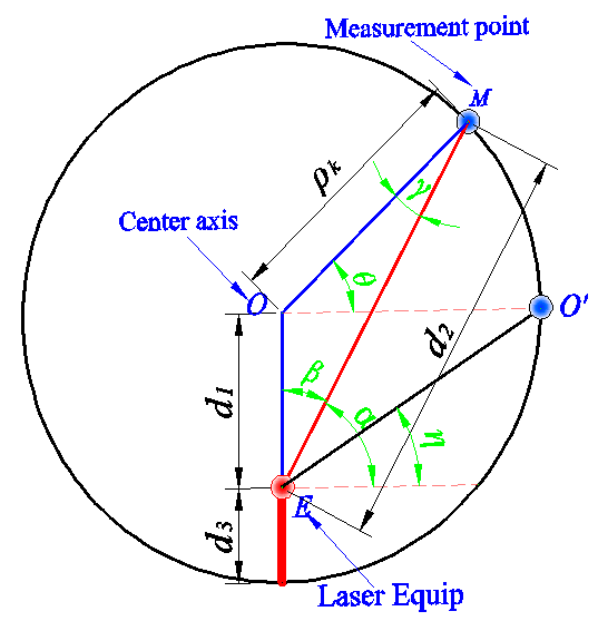

Figure 8. Geometric relationship of the laser ranging parameters.

$d_{1}$ is the vertical distance from the laser equipment to the central axis. The process for determining the value of $d_{1}$ consists of three processes. First, the total station is used to set a point $O^{\prime}$ on the wall of the karst cave with an equal elevation to that of the central axis. Second, the distance between points $E$ and $O^{\prime}$ and the measuring angle $\eta$ are measured using the laser equipment. Third, trigonometric formulae are used to obtain the value of $d_{1}$.

According to the cosine formula, the geometric expression of the cave contour (line a) $\rho_{k}$ is as follows:

$$
\rho_{k}=\sqrt{d_{1}^{2}+d_{2}^{2}-2 d_{1} d_{2} \cos \beta}
$$

As can be seen from the sine formula:

$$
\gamma=\arcsin \frac{d_{1} \sin \beta}{\rho_{k}}
$$

where $\beta=\frac{\pi}{2}-\alpha$; Formula (10) can be further derived as follows:

$$
\rho_{k}=\sqrt{d_{1}^{2}+d_{2}^{2}-2 d_{1} d_{2} \sin \alpha} .
$$


Similarly, Formula (11) can be further derived as follows:

$$
\gamma=\arcsin \frac{d_{1} \cos \alpha}{\rho_{k}}
$$

Substituting $\theta=\alpha-\gamma$ yields the following:

$$
\theta=\alpha-\arcsin \frac{d_{1} \cos \alpha}{\rho_{k}}
$$

Therefore, Formula (2) $\rho_{k}=K(\theta)$ can be derived as follows:

$$
\rho_{k}=K\left(\alpha-\arcsin \frac{d_{1} \cos \alpha}{\rho_{k}}\right)=\sqrt{d_{1}^{2}+d_{2}^{2}-2 d_{1} d_{2} \sin \alpha} .
$$

Finally, the measurement points of section $Z_{i}$ are plotted in a 3D diagram to form the cave contour (line a).

(3) Determination of the surrounding rock stability edge line (line b).

Section $Z_{i}$ in Figure 7 is selected to display the surrounding rock stability edge line (line $b$ ), as shown in Figure 9. Line $b$ is located inside the rock mass and is not visible; thus, it cannot be measured directly. In order to accurately estimate the thickness of the unstable surrounding rock, a coring survey method is adopted [27-31]. The same section is selected for the coring survey and laser ranging, but it is more difficult and time-consuming to acquire high-density coring survey points compared to performing laser ranging, and the detection accuracy is limited. Therefore, the core points can be adjusted according to the size of the cave, with no fewer than six core points for each section. Each core point should be drilled into the medium-weathered rock mass to a depth of no less than $2 \mathrm{~m}$ [32]; that is, $d_{p} \geq 2 \mathrm{~m} . d_{u}$ is the coring depth of the unstable surrounding rock. The $d_{u}$ depths of each core point are connected to draw a closed stable line b, as shown in Figure 9. Then, line b can be expressed as:

$$
\rho_{r}=d_{u} .
$$

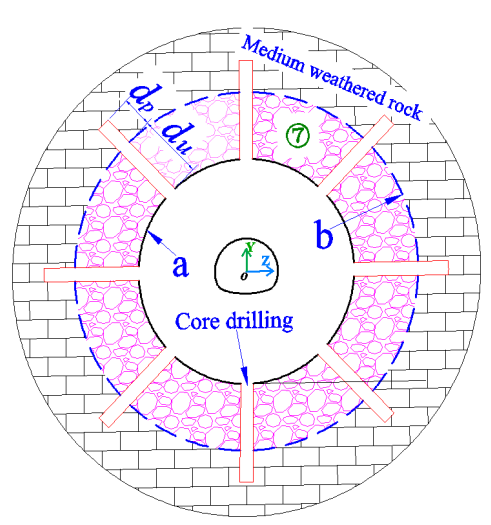

Figure 9. Determination of the surrounding rock stability edge line (line b).

(4) Determination of the filling line (line e).

The filling line (line e) of sediments such as gravel, sand, and silt in the cave was measured by the engineering measurement method, which is to measure the distance between the filling surface and the tunnel center point $O$ with a total station. This distance was set to $y_{4}$, and the value of $y_{4}$ in Formula (9) was determined. Because $d_{f}$ may be below or above the point $O, d_{f}$ satisfies Formula (16). Line e adopts the cartesian coordinate system with the central axis of the tunnel as the origin. It should 
be noted that, when determining the coring survey of line $b$, the thickness $d_{f}$ of the filling material can be determined simultaneously, as shown in Figure 10. Then, line e can be expressed as follows:

$$
y_{4}=d_{f}-K\left(-\frac{\pi}{2}\right)
$$

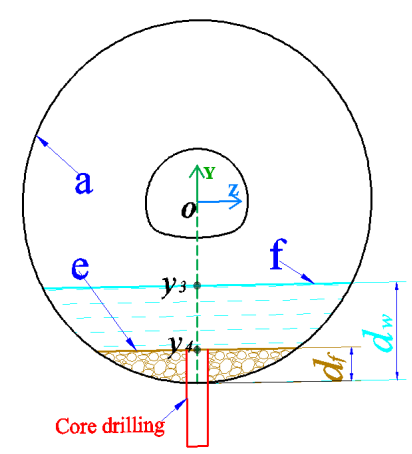

Figure 10. Determination of the filling line (line e) and water level (line f).

(5) Determination of the water level (line $\mathrm{f}$ ).

The water level (line $\mathrm{f}$ ) of the cave is spatiotemporally dependent, such that the water level should be a change interval. The variation range of the water level is obtained by observing the historical trace of the water level on the karst cave wall. The value of $y_{3}$ is the maximum over the years, and the water depth is set as $d_{w}$, as shown in Figure 10. Again, because $d_{w}$ may below or above point $\mathrm{O}, d_{w}$ satisfies Formula (18). Then, the water level line can be expressed as follows:

$$
y_{3}=d_{w}-K\left(-\frac{\pi}{2}\right)
$$

(6) Geometric drawing of SDM.

After the geometric parameters of the SDL are determined, the spatial and structural diagram of the karst cave and tunnel can be drawn, as illustrated in Figure 11. From this structural diagram, the spatial position relation between the cave and the tunnel is immediately clear, thus realizing the realistic transformation of the SDM.

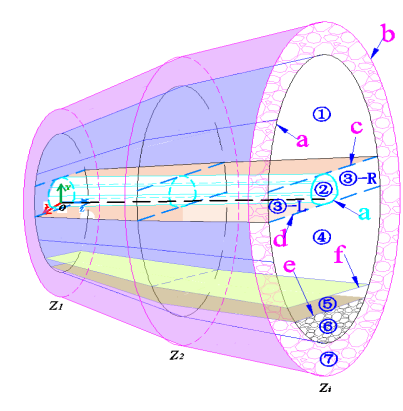

Figure 11. Geometry of the SDM.

\section{Complete Set Technology of SDM}

\subsection{General Situation}

After the establishment of the SDM, it is necessary to take corresponding technical measures to deal with the difficult problem of tunneling through a large karst cave. According to the SDM, the tunnel and the karst cave are divided into different spatial parts, and corresponding measures are taken to treat the different karst spaces. In order to ensure safety, the SDM is managed in the sequence of the cave spaces at the top, bottom, and two wings of the tunnel. 


\subsection{Treatment Technology of Karst Cave Space at the Top of Tunnel}

In order to ensure the safety of the upper space during the tunnel construction, the upper space of the cave should be treated first.

The cavern space at the top of the tunnel contains the upper space of the cave (1) and the unstable surrounding rock space (2), as shown in the Figure 3. According to the height of the upper space of the cave and the stability of the broken surrounding rock mass of the unstable surrounding rock space, methods such as supporting column reinforcement, increasing parapet reinforcement, and anchor net shotcrete support are generally adopted.

(1) When the surrounding rock stability of the karst cave is poor, and the spatial height of the upper space of the cave is large:

Generally, the unstable rock space has weak stability at the top of the tunnel, and rubble may fall or even collapse during the construction and operation of the tunnel. Moreover, the damage to the tunnel body increases in accordance with the increased height in the upper space of the cave, with higher gravitational potential energy and greater converted kinetic energy. Therefore, the unstable surrounding rock should be cleaned, after which the rock surface should be supported with an anchor net to eliminate the danger posed by the unstable surrounding rock space.

Second, the supporting column reinforcement method is adopted; the bottom of the supporting column goes deep into the complete surrounding rock, the supporting column top is installed with a prefabricated " $U$ "-type concrete slab, and the " $U$ "-type groove is filled with low-grade concrete to stop the top of the karst cave and prevent the roof of the karst cave from sagging, as shown in Figure 12.

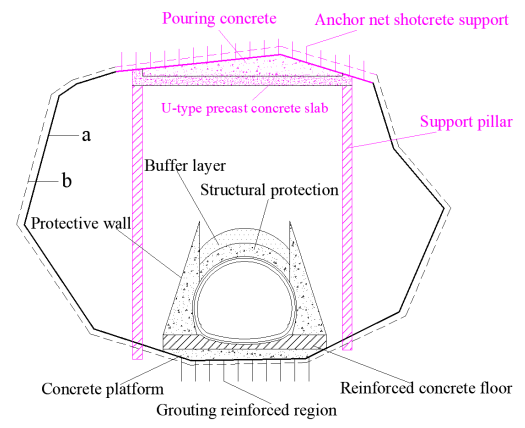

Figure 12. Schematic diagram of the supporting column treatment technology.

(2) When the surrounding rock stability of the karst cave is good, and the spatial height of the upper space of the cave is large:

When the surrounding rock of the karst cave is relatively stable, the surrounding rock cannot be treated. Instead, the anchor net shotcrete support is directly adopted to reinforce the surrounding rock at the top directly, as shown in Figure 13. For example, reference [15] a takes a similar approach.

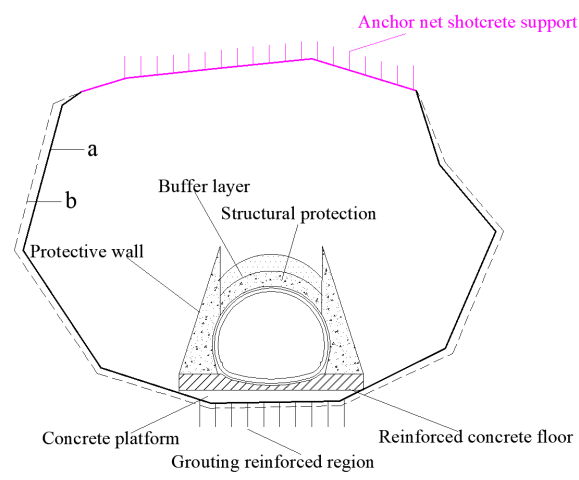

Figure 13. Schematic diagram of the treatment technology of anchor net spraying. 
(3) When the distance between the tunnel vault and the cave wall above is short:

In this condition, the height of the parapet is generally increased to make the parapet directly contact with or even go deep into the complete rock at the top of the cave wall, and lower-grade concrete is poured into the upper space above the structural protection, as shown in Figure 14. For example, reference [12] takes a similar approach.

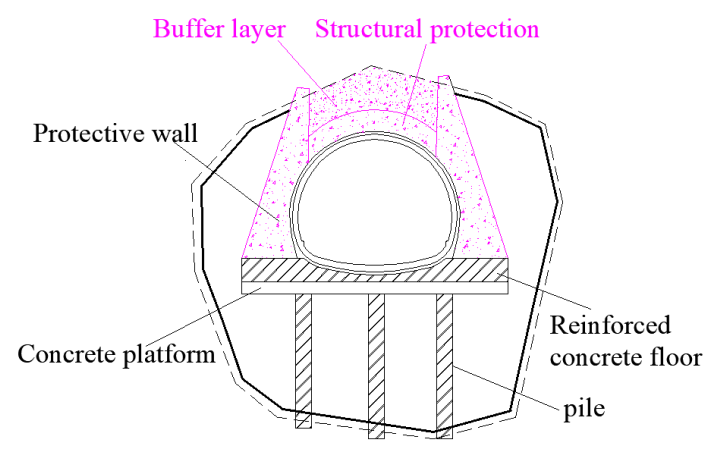

Figure 14. Schematic diagram of treatment technique for increasing the height of the protective wall.

\subsection{Treatment Teachnology of the Karst Cave at the Bottom of the Tunnel}

According to the SDM, there are four spatial parts in the karst cave space at the bottom of the tunnel: the arch bottom cave space (4), the water space (5), the filling space (6)), and the unstable surrounding rock space (7)). First, the water in the water space (5) should be removed, the backfill such as silt and gravel in the backfill space should be removed, and then the following construction judgment should be made.

(1) When the height of the karst cave at the bottom of the tunnel is large:

When the cavern space at the bottom of the tunnel is relatively high and the cave is water-rich, generally, a beam or arch is adopted to cross the cave space, which can also protect the karst water, as shown in Figure 15. For example, references $[13,15]$ take a similar approach.

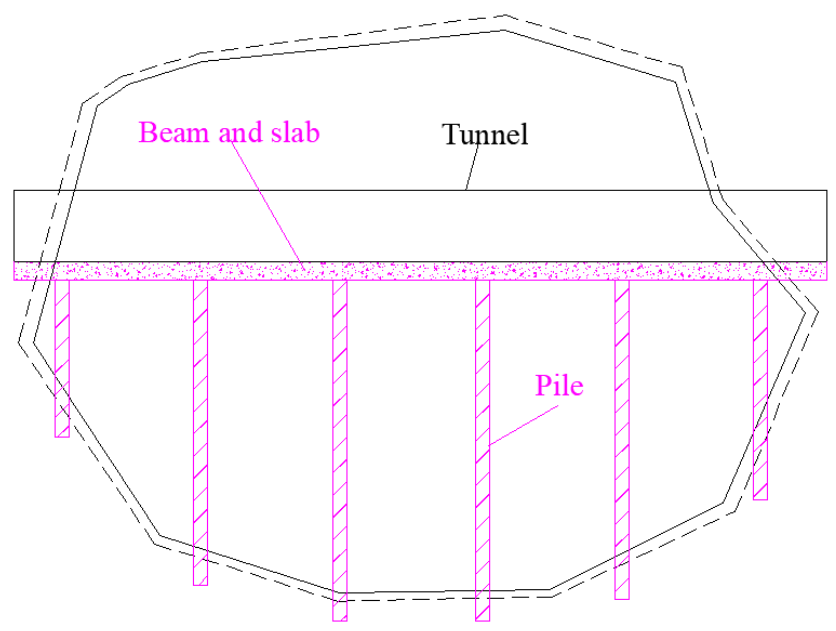

Figure 15. Schematic diagram of the treatment technique of span mode (vertical profile).

(2) When the height of the karst cave at the bottom of the tunnel is small:

When the height of the karst cave space at the bottom of the tunnel is small, grouting reinforcement and foundation replacement can be adopted, as shown in Figure 16. It is important to note that the height of the protective wall should be greater than that of the maximum water level, and the excess height should be no less than $2 \mathrm{~m}$ to prevent karst water from infiltrating above the tunnel. For example, reference [7] takes a similar approach. 


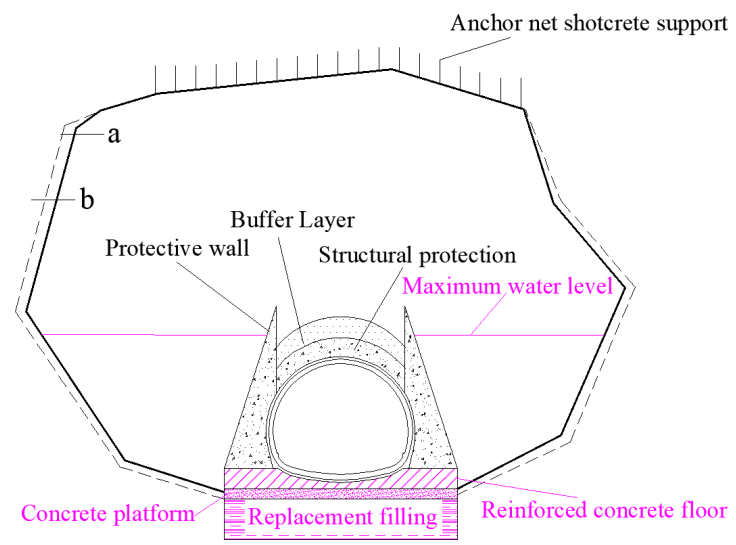

Figure 16. Foundation replacement and grouting treatment technology.

\subsection{Treatment Technology of Karst Cave Space on Two Wings of Tunnel}

According to the SDM, the two wings of the tunnel include three spaces and two space parts: the karst cave space on two wings of tunnel (3) and the unstable surrounding rock space (7)). For the treatment of the two wings of the tunnel, the distance between the tunnel and the wall of the cave should be considered, and the supporting method should be adopted accordingly.

(1) When one side of the tunnel is close to the cave wall:

If the distance between one side of the tunnel and the wall of the karst cave is relatively short, which is generally less than the maximum design thickness of the protective wall, the partial anchor should be applied to strengthen the wall of the karst cave, and then the side should be backfilled with slurry slates or pumped concrete, as shown in Figure 17. When the two wings of the cave space are less than the thickness of the parapet, slurry slates or concrete backfill can be applied to the two wings. For example, reference [18] takes a similar approach.

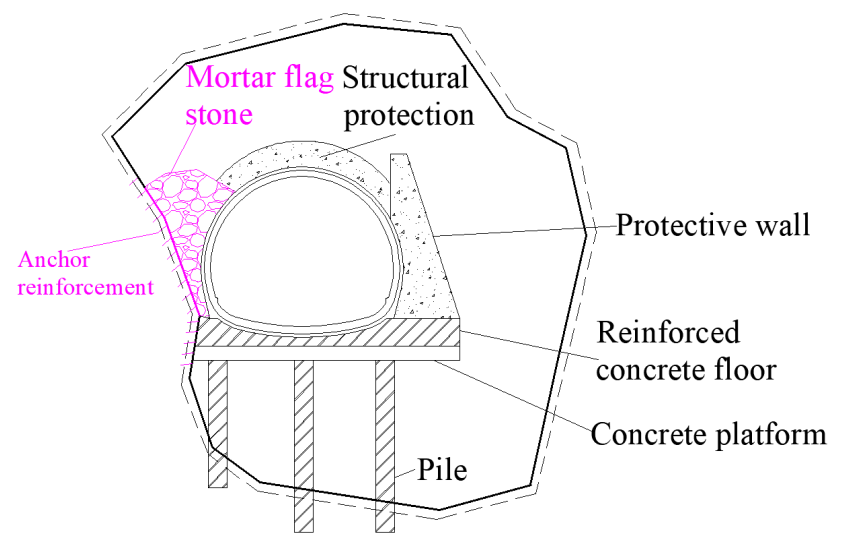

Figure 17. Treatment technology of the karst cave space in a short distance.

(2) When the distance between the two wings of the tunnel and the wall of the cave is large:

When the space of the two wings of the cave is large, it generally exceeds the maximum thickness of the parapet. It is unnecessary to consider the support of the unstable surrounding rock of the two wings, and the protective wall is used to protect the two sides directly, as shown in Figure 18. It must be emphasized that if the surrounding rock of the karst cave wall is relatively poor, the thickness and height of the protective wall should be appropriately increased to improve the protection of the tunnel body. 


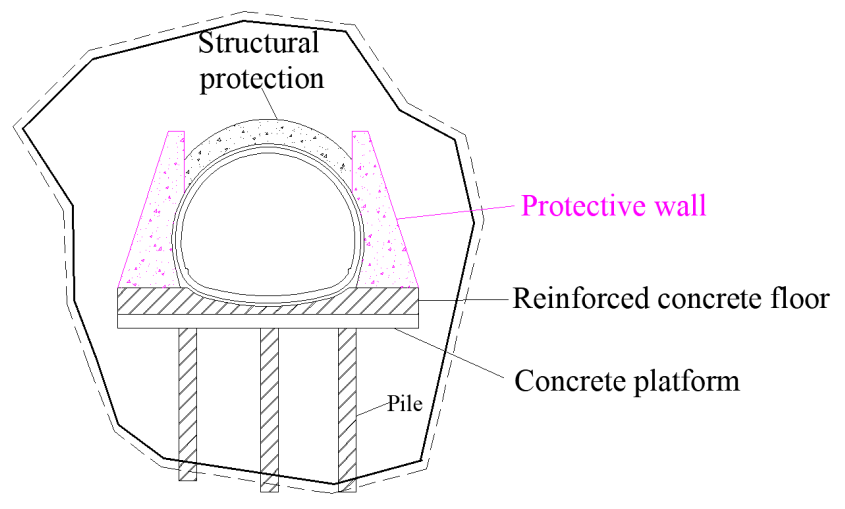

Figure 18. Treatment technique when the space of the two-wing karst cave is large.

The above treatment techniques have solved the problem of karst spaces in the upper, lower, and two wings of the tunnel. However, in practical applications, the above technologies should be analyzed, improved, supplemented, and updated according to the specific situation to make them more consistent with the field practice. At the same time, the complete set technologies for the karst cave at the top, bottom, and two wings of the tunnel are not independent from each other, but rather are interrelated systems, and the relations among the three should be considered comprehensively. In order to achieve the purposes of safety, scientific soundness, systematicity, and economy of SDM, its application should follow the following principles:

(1) High safety. The safety principle is the most basic principle of construction; the activities can proceed smoothly and orderly if safety and security are ensured.

(2) Good flexibility. Although there are fixed construction sets and methods for the treatment of karst, specific treatment measures should be formulated according to the relationship between the actual karst state and the rock mass's physical, mechanical, geotechnical, engineering geological, hydrogeological characteristics, among others.

(3) Rationality and scientificity. In short, the treatment of karst should not only comply with various laws and regulations but also consider the feasibility of treatment methods and whether they can achieve practical effects.

(4) Sustainability. The treatment of karst should not only be aimed to achieve successful treatment but also take into account the smooth conversion of construction techniques and procedures before and after the treatment, the continuity of the operation before and after the treatment, and the long-term safety and reliability of the tunnel operation.

(5) Economy. Under the premise of ensuring construction safety and project quality as well as sustainability, every effort should be made to save costs and reduce input.

(6) Realization of technology. A perfect construction plan may be designed, but it could be restricted by subjective and objective conditions such as advanced equipment, materials, and construction conditions, such that the perfect plan cannot be implemented. Therefore, the formulation of the scheme should also consider its feasibility.

\section{Engineering Application}

\subsection{General Situation}

When the construction of the Shangyuan tunnel in the Guizhou section of the Shanghai-Kunming high-speed railway reached $D 1 K 760+965$, a large filling-type karst cave was discovered. The filling material was soft and plastic-like clay, and there was a small amount of water in the cave. Through the analysis of the geological prediction results in advance, no other karst caves developed around the cave. Figure 19 shows the initial state of the karst cave discovery. This project adopted the SDM to treat the karst cave. The main application process of the SDM is shown in Figure 20. 


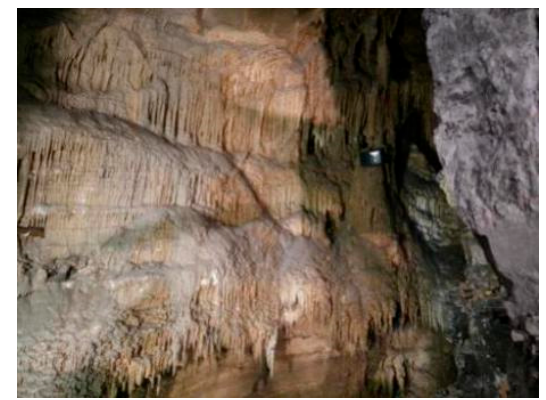

Figure 19. Development diagram of the karst cave.

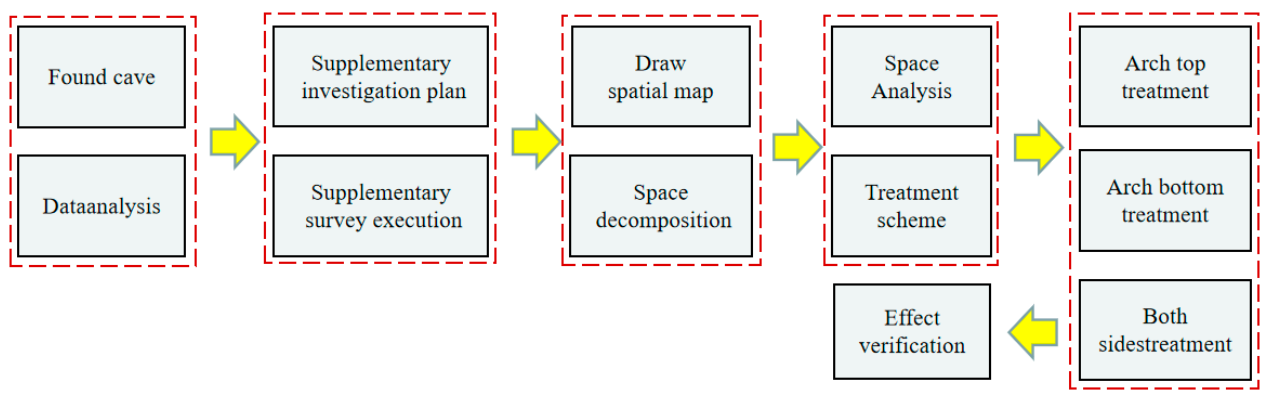

Figure 20. Application process of the spatial decomposition method.

\subsection{Supplementary Geological Survey}

According to the geometric model parameter determination method of the SDM, the central axis of the tunnel is located by means of the engineering measurement method. The longitudinal development length of the karst cave is approximately $51 \mathrm{~m}$ along the tunnel direction, and survey sections are set up every 7-8 $\mathrm{m}$ along the central axis, such that seven survey sections are constructed-namely, $Z_{1}-Z_{7}$ in Figure 21a-g. The distance of the measurement point on the wall of the cave is measured by a laser rangefinder. A core investigation is carried out on the surrounding rock of the karst cave, as shown in Figure 22a,b. Section $Z_{4}$ is taken as an example, as shown in Figure 22c. $y_{1}=-774 \mathrm{~cm}$ and $y_{2}=-356 \mathrm{~cm}$ can be obtained by surveying the filling and karst water in the karst cave. From the measurement, the distance between the measured point $\mathrm{O}$ and the filling line is $1190 \mathrm{~cm}\left(\rho_{k}\right)$. There is a small amount of blocks and silt in the cave, and the sediment thickness is approximately $30-50 \mathrm{~cm}\left(d_{f}\right)$, i.e., $y_{4}=-(1220-1240) \mathrm{cm}$. The maximum water flow is approximately $1 \mathrm{~L} / \mathrm{s}$, the water level is essentially zero, and the highest historical water level is approximately $2.4 \mathrm{~m}$ $\left(d_{w}\right)$-i.e., $y_{3}=-950 \mathrm{~cm}$. According to the coring survey, the crushing depth of the bottom surrounding rock is approximately $70 \mathrm{~cm}\left(d_{u}\right)$, and we also obtain $\rho_{k}=1260$. Here, we determine the spatial relationship of section $Z_{4}$. According to the field survey results of each section, spatial diagrams of sections $Z_{1}-Z_{7}$ were drawn, as shown in Figure 21. Then, each section is drawn into a continuous $3 \mathrm{D}$ spatial diagram to realize the modeling of geometric parameters and directly reflect the spatial relationship, as shown in Figure 23.

\subsection{Treatment Measures of Karst Cave}

According to the treatment technology of SDM discussed in Section 4 of this paper, the comprehensive treatment method is formulated based on the site situation of this project:

(1) The arch bottom cave space (4) treatment: manually clean the tunnel bottom gravel, using a $120 \mathrm{~cm}$ reinforced concrete pile reinforcement treatment, with pile transverse spacing of $5.0 \mathrm{~m}$, vertical spacing of $8.0 \mathrm{~m}$, pile bottom depth bedrock no less than $3.0 \mathrm{~m}$, pile upper section set to a $1 \mathrm{~m}$ thick C35 reinforced concrete cap, and a cap bearing platform for the C30 concrete floor. 
(2) Protective wall: C35 concrete is adopted for the protective wall. The thickness of the protective wall is not less than $2 \mathrm{~m}$ and the slope rate of the outer wall is 1:0.2.

(3) The upper space of the cave (1).

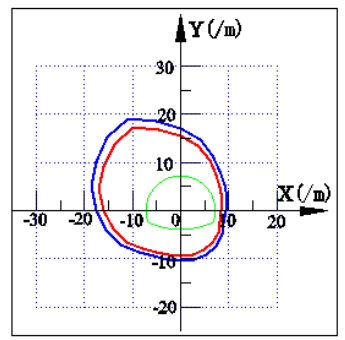

(a) $D 1 K 760+961\left(Z_{1}\right)$

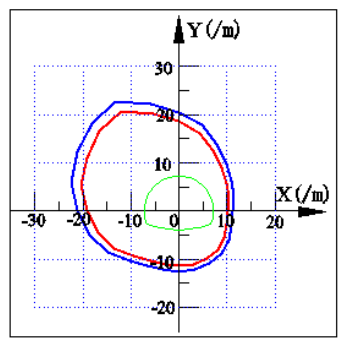

(b) $\mathrm{D} 1 \mathrm{~K} 760+954\left(\mathrm{Z}_{2}\right)$

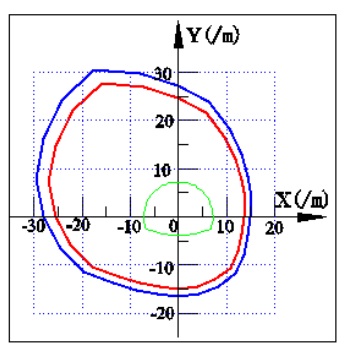

(c) $D 1 K 760+947\left(Z_{3}\right)$

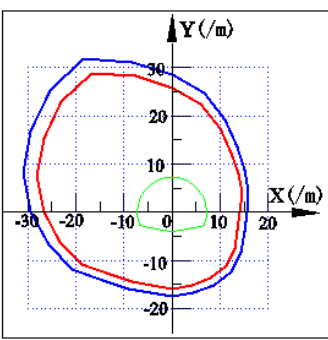

(d) $D 1 K 760+940\left(Z_{4}\right)$

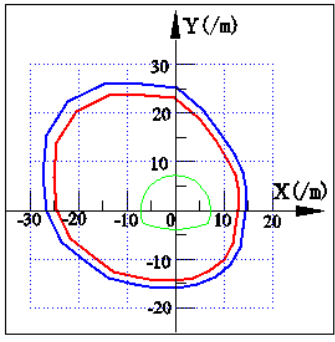

(e) $D 1 K 760+933\left(Z_{5}\right)$

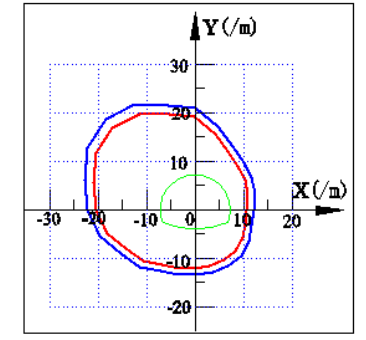

(f) $D 1 K 760+926\left(Z_{6}\right)$

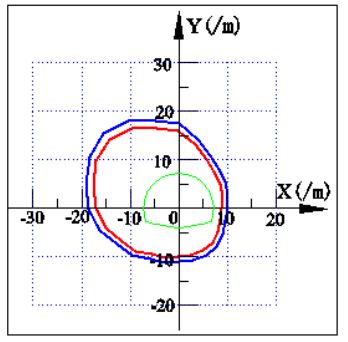

(g) $\mathrm{D} 1 \mathrm{~K} 760+919\left(\mathrm{Z}_{7}\right)$

Figure 21. Spatial relationship between the tunnel and karst cave.

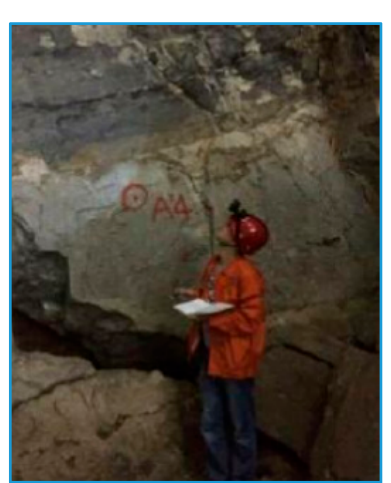

(a) Measurement points

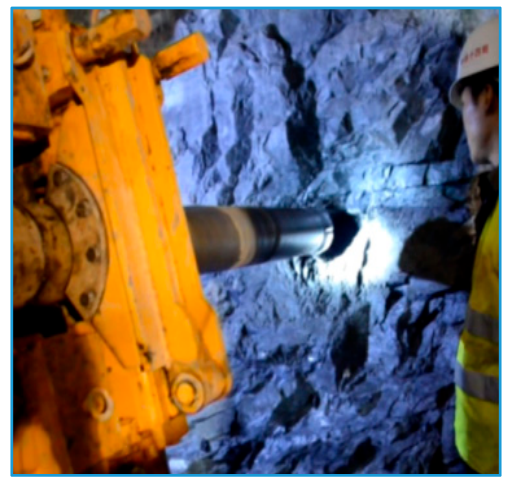

(b) Wall rock coring

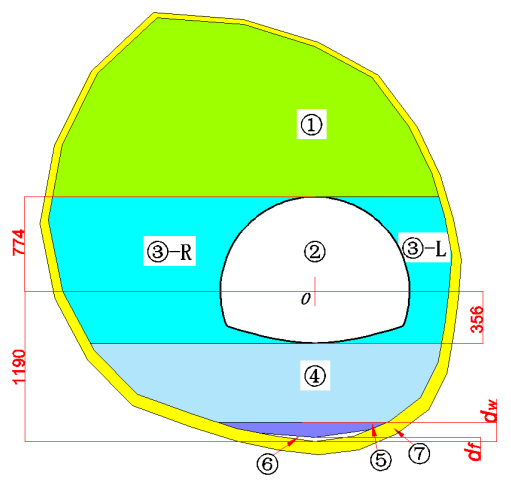

(c) D1K760 + 940 section (unit: $\mathrm{cm}$ )

Figure 22. Supplementary geological survey and section drawing.

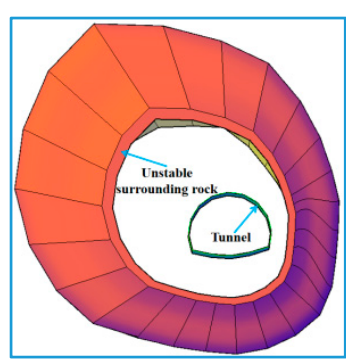

(a) Front 3D view

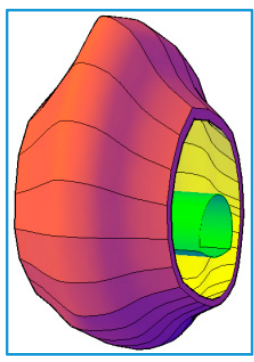

(b) Left 3D view

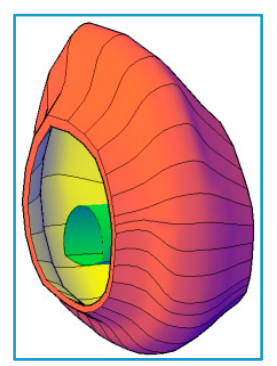

(c) Right 3D view

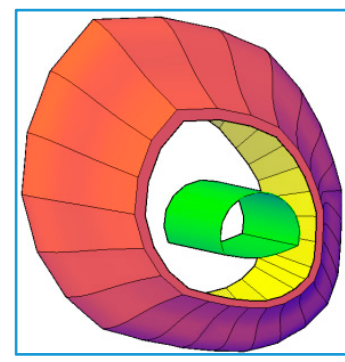

(d) Best Angle of 3D view

Figure 23. 3D spatial image. 
The unstable surrounding rock is cleared from the vault and cleaned up, and the anchor net shotcrete support is used in the cleaning area. The body of the tunnel is pumped with C30 concrete to a thickness of $1 \mathrm{~m}$ as the structural protection layer and sand to a thickness of $2 \mathrm{~m}$ as the buffer layer above the structural protection layer, as shown in Figure 24.

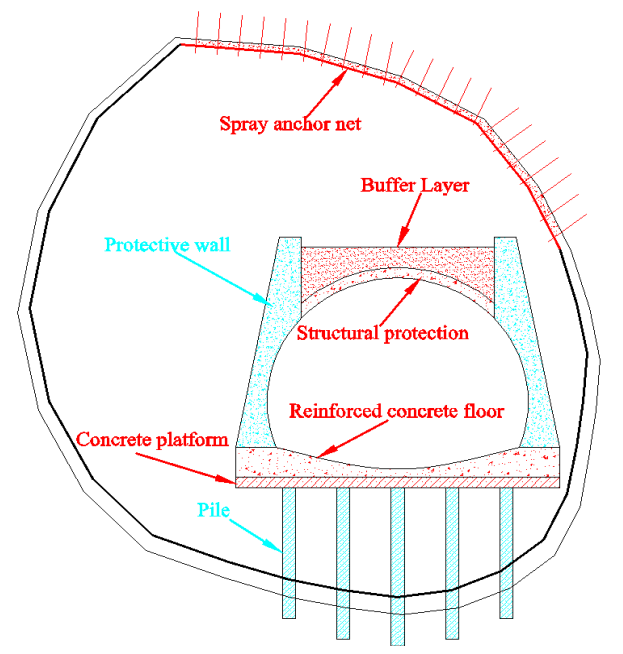

Figure 24. Treatment of the karst in section $\mathrm{Z}_{4}$.

\subsection{Effect Analysis by Monitoring Measurement}

To evaluate the treatment effects, the tunnel stability is an important factor, which includes arch settlement, clearance convergence, floor vertical displacement, surrounding rock pressure, initial support structure stress, and secondary lining stress. Because the tunnel body is not in contact with the surrounding rock, its stability is mainly reflected in the settlement of the tunnel body caused by pile settlement. Therefore, only settlement monitoring is needed for the tunnel. Three monitoring points (MS-1 to MS-3) were arranged at $D 1 K 760+955, D 1 K 760+940$, and $D 1 K 760+925$, as shown in Figure 25.

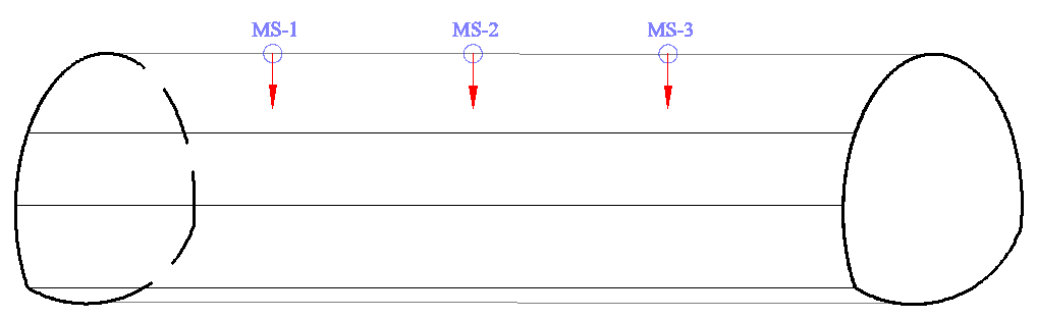

Figure 25. Arrangement of the subsidence monitoring points in the tunnel.

The monitoring data are shown in Figure 26. The settlement of the vault is accelerated in three stages and finally reaches a stable settlement state. According to the change rule of the accumulated settlement value of the vault, the settlement trend can be divided into stages I-IV. Stage I is the settlement in the later stage of lining. In this stage, monitoring activities are initiated after completing the lining construction (after the stripping). The collected data do not include the settlement during the lining construction and before the stripping. Stage II is the settlement of the structural protection layer, which is due to the increased load caused by the concrete structure protection layer on the main body of the tunnel, resulting in the acceleration of the settlement. The third stage is the construction settlement of the buffer layer. In this stage, the settlement acceleration changes owing to the increased termination caused by filling the upper part of the protection layer of the concrete structure with coarse sand. Stage IV is a stable stage. After the completion of all processes, the cumulative settlement value remains within a stable range. 


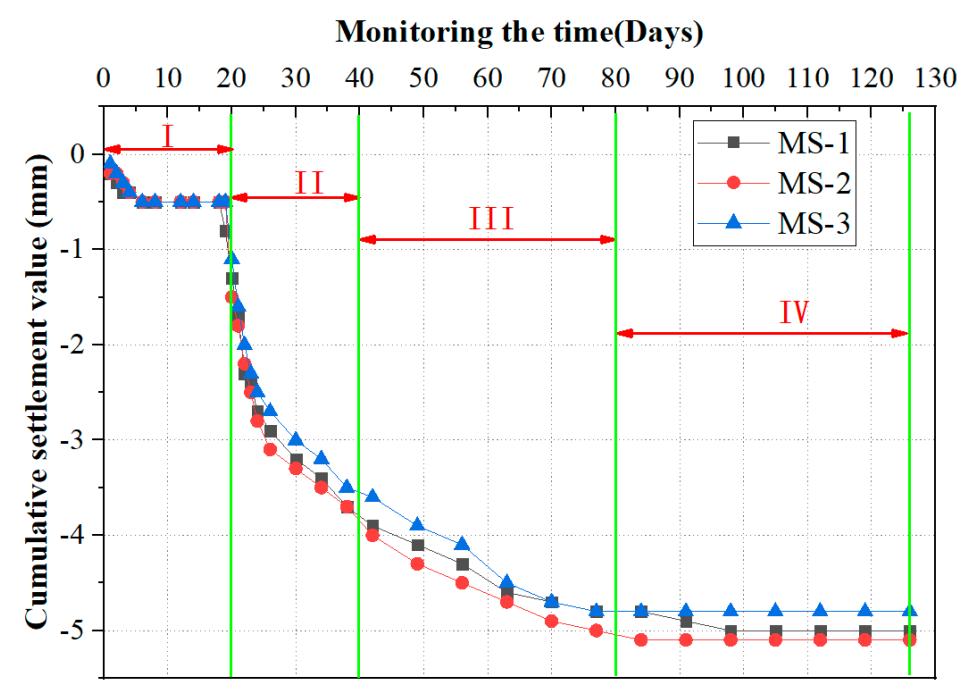

Figure 26. Monitoring of the tunnel vault settlement.

\section{Discussion}

Although important discoveries have been revealed by these studies, there are certain limitations. The results show that the SDM is mainly used for the tunnel crossing or partial crossing of large karst caves, without considering special water environmental conditions such as underground rivers and high-pressure dynamic water. When such working conditions are encountered, the SDM may not be applicable or may need to be improved for specific working conditions. At the same time, karst development is complex and variable, and the treatment techniques for karst caves are flexible and varied, as well as the supporting techniques for the SDM. As a result, builders should follow the principles of safety, science, flexibility, and sustainability during practical applications. Furthermore, the treatment technology lacks technical economic consideration based on the SDM. In general, the technical economy should be compared with other technical schemes, and the safer scheme with the lower cost should be implemented in the project.

\section{Conclusions}

In this study, the application and geometric model of the SDM are proposed, regarding the construction and operation of tunnels passing through large karst caves. The geometric parameter determination method and supporting treatment technology would provide assurance to select the karst tunnel implementation. The following conclusions are drawn from the results of this work:

(1) The SDM is proposed. The SDL is used to divide the space of the large karst cave into eight parts. Compared with traditional construction methods, this present method provides a means to conduct a spatial analysis which is more straightforward and clear for tunnels through large karst caves.

(2) The geometric model of the SDM is established. Cartesian and cylindrical coordinate systems are used to describe the geometric parameters of the SDL. A method for the site investigation of tunnels and large karst caves is proposed. The geometric parameters of the SDL are determined to realize the spatial geometric description of the SDM.

(3) According to the SDM, spatial treatment technologies for the top, bottom, and two wings of the tunnel are proposed. It is emphasized that the overall technology application should follow the principles of safety, flexibility, science, sustainability, and economy.

Author Contributions: Conceptualization, Z.S. and Q.W.; methodology, J.L. and Z.Z.; investigation, R.S. and Y.L.; data curation, Y.Y. and F.W. and H.S.; writing-review and editing, C.P.; All authors have read and agreed to the published version of the manuscript. 
Funding: This research was funded by the National Natural Science Foundation of China (NSFC) (No. 51778351) and SDUST Research Fund (No. 2018TDJH101).

Conflicts of Interest: The authors declare no conflict of interest.

\section{Nomenclature}

$\rho \quad$ polar diameter

$\theta \quad$ polar angle

Z a plane parallel to plane $\mathrm{XOY}$

$i \quad$ a section is numbered $i$

$D_{1} \quad$ spacing of sections

$\rho_{k} \quad$ geometric expression of the cave contour

$\rho_{r} \quad$ geometric expression of the surrounding rock stability edge line

$\rho_{t} \quad$ geometric expression of the tunnel contour line

$y_{1} \quad$ geometric expression of the tunnel top line

$y_{2} \quad$ geometric expression of tunnel bottom line

$y_{3} \quad$ geometric expression of the water level line

$y_{4} \quad$ geometric expression of filling line

$d_{1} \quad$ vertical distance from the laser equipment to the central axis

$d_{2} \quad$ distance between the laser equipment and the proposed measurement point

$d_{3} \quad$ height of the laser equipment tripod

$d_{u} \quad$ depth of the unstable surrounding rock

$d_{p} \quad$ depth of a borehole into medium-weathered rock mass

$d_{f} \quad$ thickness of the filling in the cave

$d_{w} \quad$ depth of the water in the cave

$\alpha \quad$ angle between $d_{2}$ and the horizontal direction

$\beta \quad$ angle between $d_{2}$ and the vertical direction

$\gamma \quad$ angle between $d_{2}$ and $\rho_{k}$

\section{References}

1. Zhou, Z.F.; Zhang, S.Y.; Xiong, K.N.; Li, B.; Tian, Z.H.; Chen, Q.; Yan, L.H.; Xiao, S.Z. The spatial distribution and factors affecting karst cave development in Guizhou Province. J. Geogr. Sci. 2017, 27, 1011-1024. [CrossRef]

2. Wei, Y.Y.; Sun, S.L.; Huang, J.J.; Hua, X.Q. A study on karst development characteristics and key control factors of collapse in Xuzhou, eastern China. Carbonate Evaporite 2018, 33, 359-373. [CrossRef]

3. Sun, S.Q.; Li, L.P.; Wang, J.; Shi, S.S.; Song, S.G.; Fang, Z.D.; Ba, X.Z.; Jin, H. Karst Development Mechanism and Characteristics Based on Comprehensive Exploration along Jinan Metro, China. Sustainability 2018, 10, 3383. [CrossRef]

4. Gao, W.F.; Shi, L.Q.; Han, J.; Zhai, P.H. Study on control water of Ordovician aquifer: A coal mine of Feicheng mining area, China. Carbonate Evaporite 2020, 35. [CrossRef]

5. Li, S.C.; Wu, J. A multi-factor comprehensive risk assessment method of karst tunnels and its engineering application. Bull. Eng. Geol. Environ. 2019, 78, 1761-1776. [CrossRef]

6. Gutierrez, F.; Parise, M.; De Waele, J.; Jourde, H. A review on natural and human-induced geohazards and impacts in karst. Earth-Sci. Rev. 2014, 138, 61-88. [CrossRef]

7. Li, S.C.; Zhou, Z.Q.; Ye, Z.H.; Li, L.P.; Zhang, Q.Q.; Xu, Z.H. Comprehensive geophysical prediction and treatment measures of karst caves in deep buried tunnel. J. Appl. Geophys. 2015, 116, 247-257. [CrossRef]

8. Cui, Q.L.; Wu, H.N.; Shen, S.L.; Xu, Y.S.; Ye, G.L. Chinese karst geology and measures to prevent geohazards during shield tunnelling in karst region with caves. Nat. Hazards 2015, 77, 129-152. [CrossRef]

9. Shi, Z.Y.; Wang, Q.B.; Xu, L. Experimental Study of Cement Alkali-Resistant Glass Fiber (C-ARGF) Grouting Material. Materials 2020, 13, 605. [CrossRef]

10. Wang, Q.B.; Zhu, Q.K.; Shao, T.S.; Yu, X.G.; Xu, S.Y.; Zhang, J.J.; Kong, Q.L. The rheological test and application research of glass fiber cement slurry based on plugging mechanism of dynamic water grouting. Constr. Build. Mater. 2018, 189, 119-130. [CrossRef] 
11. Fan, H.B.; Zhang, Y.H.; He, S.Y.; Wang, K.; Wang, X.L. Hazards and treatment of karst tunneling in Qinling-Daba mountainous area:overview and lessons learnt from Yichang-Wanzhou railway system. Environ. Earth Sci. 2018, 77, 679. [CrossRef]

12. Chen, H.W.; Sha, C. Stability Analysis of Surrounding Rock and Treatment Structures in Superlarge Karst Cave of Naqiu Tunnel. Adv. Civ. Eng. 2018, 2018, 4842308. [CrossRef]

13. Garasic, M.; Kovacevic, M.S.; Juric-Kacunic, D. Investigation and Remediation of the Cavern in the Vrata Tunnel on the Zagreb-Rijeka Highway (Croatia). Acta Carsol. 2010, 39, 61-77. [CrossRef]

14. Yang, J.S.; Zhang, C.; Fu, J.Y.; Wang, S.Y.; Ou, X.F.; Xie, Y.P. Pre-grouting reinforcement of underwater karst area for shield tunneling passing through Xiangjiang River in Changsha, China. Tunn. Undergr. Space Technol. 2020, 100, 103380. [CrossRef]

15. Li, K. Case Study on Coping with Super large Karst Cave in Construction of Yanwan Tunnel. Tunn. Constr. 2015, 35, 79-82. (In Chinese)

16. Zhang, Y.L.; Tian, K. Treatment and construction technology of large karst cave in limushan tunnel. Highway 2019, 9, 196-199. (In Chinese)

17. Yuan, Y.C.; Li, S.C.; Li, L.P.; Shi, S.S.; Zhou, Z.Q.; Lei, T. Study on comprehensive forecast and treatment scheme of large karst cave during construction of karst tunnel. Modern Tunn. Technol. 2015, 52, 192-197. (In Chinese)

18. Tan, L.J. Discussion on Treatment of Big Karst Cave in Niulugou Tunnel. Constr. Des. Proj. 2019, 9, 79-81. (In Chinese)

19. He, P.J. Construction Technology of Yesanguan Tunnel Crossing Large Karst Cave Filling with High-pressure and Water-rich Block Stone. Rail Way Constr. Technol. 2017, 5, 85-89. (In Chinese)

20. Tian, C.; Yang, X.; Sun, H.; Liu, Y.; Hu, Q. Experimental study on the overburden movement and stress evolution in multi-seam mining with residual pillars. Energy Sci. Eng. 2019, 7, 3095-3110. [CrossRef]

21. Wang, P.; Jia, H.J.; Zheng, P.Q. Sensitivity Analysis of Bursting Liability for Different Coal-rock Combinations Based on Their Inhomogeneous Characteristics. Geomat. Nat. Hazards Risk 2020, 11, 149-159. [CrossRef]

22. Department of Mathematics, Tongji University. Chapter 10 Multiple Integral. In Advanced Mathematics, 6th ed.; Higher Education Press: Beijing, China, 2007; pp. 129-176. ISBN 978-7-04-021277-8. (In Chinese)

23. Basantes, J.; Godoy, L.; Carvajal, T.; Castro, R.; Toulkeridis, T.; Fuertes, W.; Aguilar, W.; Tierra, A.; Padilla, O.; Mato, F; et al. Capture and processing of geospatial data with laser scanner system for 3D modeling and virtual reality of Amazonian Caves. In Proceedings of the 2nd IEEE Ecuador Technical Chapters Meeting (ETCM), Salinas, Ecuador, 16-20 October 2017; IEEE: New York, NY, USA, 2017.

24. Jaillet, S.; Delannoy, J.J.; Genuite, K.; Hoblea, F.; Monney, J. Karst and cave topographic images: 2D representations and 3D technologies, between reality and imagination. Geomorphologie 2019, 25, 191-205. [CrossRef]

25. Liu, X.L.; Li, X.B.; Li, F.B.; Zhao, G.Y.; Qin, Y.H. 3D cavity detection technique and its application based on cavity auto scanning laser system. J. Cent. South Univ. Technol. 2007, 15, 285-288. [CrossRef]

26. Perez-Flores, M.A.; Ochoa-Tinajero, L.E.; Villelay, M.A. Three-dimensional inverse modeling of EM-LIN data for the exploration of coastal sinkholes in Quintana Roo, Mexico. Nat. Hazard Earth Syst. 2019, 19, 1779-1787. [CrossRef]

27. An, L.; Jin, C.Y.; Liu, D.; Ding, C.G.; Dai, X.H. Mechanism of core discing in the relaxation zone around an underground opening under high in situ stresses. Bull. Eng. Geol. Environ. 2018, 77, 1179-1189. [CrossRef]

28. Tian, F.; Lu, X.B.; Zheng, S.Q.; Zhang, H.F.; Rong, Y.S.; Yang, D.B.; Liu, N.G. Structure and Filling Characteristics of Paleokarst Reservoirs in the Northern Tarim Basin, Revealed by Outcrop, Core and Borehole Images. Open Geosci. 2017, 9, 266-280. [CrossRef]

29. Wang, J.; Li, L.P.; Shi, S.S.; Sun, S.Q.; Ba, X.Z.; Zhang, Y.J. Fine Exploration and Control of Subway Crossing Karst Area. Appl. Sci. Basel 2019, 9, 2588. [CrossRef]

30. Saddek, B.; Chemseddine, F.; Djamel, B.; Nabil, B. Surface and Subsurface Investigations for the Detection and Mapping of Underground Karst Cavities in MChentel Area, Cheria Basin, Northeast of Algeria. J. Cent. South Univ. Technol. 2019, 93, 228-234. [CrossRef] 
31. Tian, C.; Liu, Y.; Yang, X.; Hu, Q.; Wang, B.; Yang, H. Development characteristics and field detection of overburden fracture zone in multiseam mining: A case study. Energy Sci. Eng. 2020, 8, 602-615. [CrossRef]

32. GB50021-2001. Code for Investigation of Geotechnical Engineering; Mouhurd: Beijing, China, 2002. (In Chinese)

Publisher's Note: MDPI stays neutral with regard to jurisdictional claims in published maps and institutional affiliations.

(C) 2020 by the authors. Licensee MDPI, Basel, Switzerland. This article is an open access article distributed under the terms and conditions of the Creative Commons Attribution (CC BY) license (http://creativecommons.org/licenses/by/4.0/). 